\title{
EVALUACIÓN CRÍTICA DE LA EFICACIA DEL CAMINO DE MENOR COSTE PARA EL ESTUDIO PREDICTIVO DEL QHAPAQ NAN
}

\author{
CRITICAL ASSESMENT OF THE EFFICACY OF THE LEAST-COST PATH IN THE \\ PREDICTIVE STUDY OF QHAPAQ NAN
}

\author{
Pablo Mignone ${ }^{1}$
}

\begin{abstract}
El sistema vial inkaico es el objeto arqueológico más grande de las Américas por sus $60.000 \mathrm{~km}$ de extensión. Es en consecuencia un rasgo de primer orden para estudiar y preservar desde una perspectiva científica y patrimonial, por lo cual se han comenzado a adoptar distintas metodologías para su registro e interpretación que incluyen recientemente la modelización geomática. En este marco, el presente trabajo tiene como objetivo evaluar si el uso de técnicas de los Sistemas de Información Geográfica (o SIG) como el cálculo de caminos de menor coste (Least Cost Paths), de uso corriente en arqueología, puede ser aplicado al estudio del Qhapaq Ñan o si por el contrario, y como muestran los pocos antecedentes al respecto, no es del todo adecuado y es preferible adoptar otras que incluyan una mirada menos economicista y más abarcadora de la experiencia humana en el paisaje. Para evaluar la aplicabilidad de esa técnica espacial se estudiaron cuatro tramos de caminos inkaicos de las zonas de Prepuna y Puna de la provincia de Salta, Argentina, que durante la ocupación cusqueña fueron claves tanto en el control de las actividades productivas como en el aspecto simbólico.
\end{abstract}

Palabras claves: caminos de menor coste, Qhapaq Ñan, predictibilidad.

The Inca road system, with an extension of 60,000 km, is the largest archaeological object in the Americas. This substantial characteristic makes it an object of study and preservation from a scientific and heritage perspective. Accordingly, different methodologies have begun to be adopted to record it and interpret it, including geomatic modeling. In this context, this work aims to assess whether the use of Geographic Information Systems (GIS) techniques, such as the Least-Cost Path calculation, which is commonly used in archeology, can be applied to the study of the Qhapaq Nan, or, on the contrary, and as the few historical data show in this regard, it is better to use other less economistic techniques that include a more comprehensive look of the human experience in the landscape. To assess the applicability of this space technique, four sections of Inca roads were studied in the Prepuna and Puna areas of the province of Salta, Argentina, which, during the Cuzco occupation, played a key role in the control of productive activities and in symbolic terms.

Key words: Least-Cost Paths, Qhapaq Ñan, predictability.

Las investigaciones sobre el Qhapaq Nan han resaltado su gran magnitud en cuanto obra de ingeniería prehispánica (Matos 2015), el enorme rol simbólico que cumplió al ser la materialización del poder político en los territorios conquistados (Hyslop 1992) y su protagonismo como medio de sostenimiento económico, ideológico y social del Tawantinsuyu (Moralejo 2018). Si bien son incontables los antecedentes sobre la vialidad estatal, poco se ha desarrollado acerca de la relación entre ella y los factores ambientales en cuanto a las posibilidades que los mismos brindan para el establecimiento y funcionamiento de los caminos.
En los últimos años, sin embargo, este tipo de estudio se ha comenzado a realizar de manera creciente empleando los Sistemas de Información Geográfica (SIG en adelante), aunque centrando el análisis en cortos tramos de caminos (no más de $5 \mathrm{~km}$ ), con una base cartográfica de poca resolución (de 30 a 90 metros por píxel, salvo excepciones), para modelar desde una lectura bibliográfica la influencia de algunas variables ambientales, como la pendiente del terreno o la cercanía a ríos, en el trazado de las vías de comunicación.

Buscamos entonces aportar al tema creando mediante un SIG caminos de menor coste (Least-cost

\footnotetext{
${ }^{1}$ Instituto de Investigaciones en Ciencias Sociales y Humanidades (ICSOH), Universidad Nacional de Salta, CONICET, Salta, Argentina.pmignone@ hotmail.com
}

Recibido: noviembre 2018. Aceptado: marzo 2020. 
Path o LCP en adelante) que permitan identificar los factores naturales que influyeron en la configuración de cuatro vías prehispánicas de más de $150 \mathrm{~km}$ de extensión registradas en las zonas áridas y semiáridas de la provincia de Salta, Argentina, empleando cartografía digital de una resolución adecuada para captar los accidentes del terreno (de 12,5 m por píxel), evaluando así los alcances y limitaciones de las prestaciones de los modelos predictivos informáticos para el estudio de este rasgo tan conspicuo del poder estatal. Se modelarán para este objetivo las pendientes, la rugosidad del terreno, la concentración de la vegetación, la velocidad del tránsito y el gasto energético, para evaluar si las técnicas de uso corriente nos pueden dar cuenta de la dialéctica entre los rasgos culturales y el medio ambiente.

Se propone que a pesar de ser el LCP una herramienta muy útil para identificar áreas potenciales de hallazgo en determinadas circunstancias, sus limitaciones nos llevan a buscar una alternativa metodológica (un mapa de sensibilidad arqueológica de cálculo sencillo), que simplifique el modelado informático. Se indica en consecuencia al cálculo de LCP como una instancia de partida, complementaria con otras aproximaciones de índole religiosa o simbólica que permita dar una idea más acabada de toda la complejidad de la vialidad inkaica.

\section{Antecedentes y Marco Teórico}

Sin caer en determinismos ambientales, lo que se busca es tanto reconstruir de forma realista los espacios de circulación humano mediante el modelado informático, como estudiar la relación dialéctica entre los seres humanos y los sistemas naturales de forma integrada y no lineal (o "ecodinámica humana" según Fitzhugh et al. 2019), entendiendo al registro arqueológico, especialmente la infraestructura de la comunicación representada por los caminos, como un espacio continuo con diferentes densidades y no necesariamente como el predominio de concentraciones puntuales de evidencia arqueológica en bolsones (Ebert et al. 1987).

La ecodinámica humana así entendida implica considerar los "proporcionamientos" (affordances), término acuñado por Gibson en 1977 que significa el conjunto de propiedades ambientales relativas al comportamiento humano. Esta noción caracteriza lo que el ambiente puede ofrecer potencialmente a los individuos en relación a las propiedades y las habilidades de esos individuos de actuar en dicho ambiente (para moverse, obtener alimento, entre otras actividades). Implica en otros términos la interdependencia, siempre según Gibson, entre el ambiente y los individuos (Verhagen et al. 2019). Como sostienen los autores citados, la premisa básica del modelado de los caminos y el movimiento en arqueología es el hecho de que durante el tránsito o movilidad de los seres humanos a través del paisaje, el proporcionamiento es el potencial ofrecido a un individuo dentro de un ambiente específico de moverse a lo largo de éste en términos de las ventajas o desventajas que las mismas presentan para lograr su cometido, incluso si el agente no es consciente de las características del entorno que está eligiendo. Mediante el SIG podemos identificar y emplear los proporcionamientos del ambiente para el movimiento a fin de calcular el movimiento potencial de una serie de lugares (Llobera 2000 en Verhagen et al. 2019:219).

Una de las prestaciones que tienen los SIG para modelar esta relación dialéctica entre los seres humanos y su entorno corresponde al llamado "algoritmo de menor coste" (least cost algorithm en inglés), cálculo por el cual se evalúa la forma en que los individuos despliegan sobre el paisaje las estrategias más adecuadas para sortear obstáculos con el menor gasto de recursos. Lo que significa en otros términos que los seres humanos limitarían los costos de atravesar el paisaje empleando diversos medios técnicos y cognitivos para buscar los caminos más adecuados que faciliten el desplazamiento ${ }^{1}$.

Tal como indican Lucero et al. (2014) esta postura asume que los seres humanos buscan economizar su comportamiento desde el principio del menor esfuerzo elaborado por Zipf, principio que si bien tiene su objeto original en el uso del lenguaje, ha sido aplicado desde su formulación en 1950 a distintas realidades entre las que se encuentra el desplazarse por el paisaje limitando los costos y buscando la mayor accesibilidad.

Debido al relieve accidentado de Los Andes se considera a la pendiente como un factor de primer orden en el tránsito de los grupos humanos y en la configuración de los caminos. Sin embargo, existen otros factores relevantes como el tipo de suelo, la cobertura vegetal de la superficie terrestre, la hidrología, la geomorfología, a lo que debemos sumarle los factores culturales, como la presencia de facciones rivales, de hitos paisajísticos sagrados o de tabúes religiosos que tanto pueden propiciar como limitar el desplazamiento de las personas (Verhagen 2017).

La tendencia actual del empleo de los caminos de menor coste en arqueología espacial es calcular los costes de atravesar una determinada topografía, el gasto de energía implicado, la cercanía a otros sitios arqueológicos, lugares sagrados, fuentes de agua y depósitos de materias primas (Wheatley y Gillings 2004).

Siguiendo esta línea, Howey (2007), por ejemplo, integra los criterios de pendiente, hidrología, y cobertura vegetal para investigar las relaciones intertribales en el periodo Tardío de Michigan, comprobando que las vías 
de comunicación permitían el acceso a características culturalmente importantes como los terraplenes Missaukee.

El estudio de redes a partir de la teledetección y SIG en Perú ha demostrado ser sumamente útil para investigar las relaciones entre las culturas andinas del pasado y su medio ambiente, en medios geográficos hostiles que plantean un difícil acceso a los sitios arqueológicos (Parcak 2009:17).

El SIG se ha utilizado también para identificar si los sitios del pasado se encontraban inmersos en relaciones de larga distancia. Por ejemplo, Stanish et al. (2010) realizaron una prospección en la cuenca suroeste del Titicaca con el fin de evaluar la naturaleza del comercio de larga distancia de Tiwanaku y su colonia primaria de Moquegua.

A través de la investigación facilitada por el LCP los autores descubrieron pruebas casi continuas de ocupación Tiwanaku a lo largo de los senderos y caminos entre Tiwanaku y Moquegua. Ellos también determinaron que, a diferencia del Inka, Tiwanaku no mantenía estaciones de camino ni desarrollaba un sistema de carreteras y que en su lugar se basó en las caravanas de camélidos que requieren un camino de bajo costo para viajar (Stanish et al. 2010).

White (2012) por su parte, puso a prueba la creencia que los senderos de Papaguería occidental (sudoeste de Arizona) se utilizaron principalmente para viajes de larga distancia, comprobando en su lugar que los caminos permitían un movimiento de corto alcance para la comunicación de los residentes de la zona a nivel intrarregional (White 2012).

Rademaker et al. (2012), realizaron otro tanto comparando varios LCP basados en la pendiente del terreno y la velocidad de marcha estimada para calcular el gasto energético en el desplazamiento entre el sitio paleoindio de Quebrada Jaguay en la costa meridional del Pacífico peruano y la fuente de obsidiana Alca. Para estos autores, el LCP resultó ser un método útil para predecir áreas de prospección arqueológica en los Andes, particularmente para cazadores recolectores ya que sus movimientos se basan típicamente en la eficiencia económica (Rademaker et al. 2012).

En Arequipa, Tripcevich (2008) desarrolló un estudio etnoarqueológico del movimiento de una caravana de llamas para evaluar si el aprovechamiento de distintas fuentes de materia prima para la confección de instrumentos líticos recuperados en prospecciones y excavaciones correspondían con el trazado de rutas de intercambio cimentadas en el caravaneo prehispánico. En base a la información digital de las pendientes obtenidas de un Modelo Digital de Elevaciones (en adelante DEM por sus siglas en inglés), el foco se centró en la velocidad de transporte de la caravana y en cómo fueron conducidas a través de las mejores pendientes, obteniendo también valiosa información acerca de distintos aspectos del manejo de los rebaños, el uso de los corrales, prácticas rituales y la selección de caminos en las montañas, entre otros aspectos de interés.

En virtud de los rasgos culturales compartidos entre sociedades del NO de la provincia argentina de San Juan y el Norte Semiárido de Chile entre los años 290 AC y 670 DC, Lucero et al. (2014) buscan establecer las posibles vías de circulación en base a caminos de menor coste creados mediante un SIG. Para ello emplearon dos formas de modelar la velocidad de marcha, el algoritmo creado por Tripcevich (2008) y el de Tobler (1993), que permite estimar la velocidad y el tiempo necesario (obtenidos de la observación de marcha de la infantería suiza), o costo acumulado, de transitar por un paisaje en base al cociente del cambio vertical de la pendiente y el cambio horizontal de la misma.

En cuanto a los caminos inkaicos, no es extraña a la temática la idea del peso de los factores ambientales en su configuración y derrotero. Hyslop (1992), por ejemplo, remarca que el análisis del Qhapaq Ñan debe considerar las superficies naturales donde fueron construidos los caminos, tanto en su constitución lítica (arena, roca) y de potencial económico (tierras agrícolas, estepas de gramíneas y superficies inundables), como en su geomorfología, con especial detenimiento en las pendientes. Vitry (2004), por su parte, menciona que los lugares elegidos para su construcción son en cierta forma determinantes para la ingeniería implicada e influyen en no poca medida en la percepción visual desde y hacia los caminos y estructuras asociadas.

Las aplicaciones del SIG al estudio de la vialidad inkaica aún son poco numerosas. Entre ellas contamos con el aporte de De Feo y Gobo (2007), quienes compararon estadísticamente con información de campo un tramo de $5 \mathrm{~km}$ de camino inkaico y un camino de menor coste en la localidad de las Cuevas, en el ámbito de puna de la provincia de Salta, demostrando que el modelo concuerda con el Qhapaq Ñan en una porción muy pequeña del mismo.

Por su parte, Matsumoto (2008) emplea la información publicada por Hyslop para estudiar tres caminos inkaicos en Perú: las conexiones Cañar-Azuay, Lambayaque-Moche y Cajamarca-Huamachuco. El estudio se topa con varias dificultades, entre ellas la falta de trabajos de campo ya que emplea los mapas realizados por Hyslop en la década de 1970, de los cuales el autor desconoce el sistema geodésico y datum de sus coordenadas.

Otra de las dificultades es la baja resolución del modelo digital de elevaciones elegido, de $90 \mathrm{~m}$ de resolución (cada un píxel significa $90 \mathrm{~m}$ en el terreno), que le impide tener en cuenta numerosos detalles del terreno. Concluye el autor que el LCA no es buen predictor del camino inkaico, no por la falta de trabajo 
de campo y las dificultades del registro de una variable continua en el terreno, como podríamos pensar, sino por las consideraciones propias de la percepción humana, para la cual no existe un camino económico óptimo sino, cuando menos, un corredor que incluye cierta variedad de soluciones para la confección y trazado de una vía.

Magee (2015), por su parte, emplea cuatro rutas calculadas a partir de la pendiente, la cercanía a ríos, la eficiencia energética y la distancia para inferir la posible ubicación de la hoy desaparecida vía que conectaba Cusco con Vilcashuaman, partiendo del conocimiento bibliográfico de sus antiguas ciudades inkaicas. La autora identifica también la incapacidad propia del LCA de encontrar rutas secundarias, como bifurcaciones y trifurcaciones en el camino, ya que el cálculo se basa exclusivamente en el hallazgo de la ruta más eficiente para comunicar dos lugares (Magee 2015:84).

En el ámbito de la arqueología de alta montaña, Racoviteanu (2004) modela varios LCP combinando la variable pendiente con sus derivadas, como tiempo de marcha y gasto energético, para evaluar si las construcciones inkaicas erigidas en los santuarios de altura Coropuna (6.377 msm) y Pichu Pichu (5.634 $\mathrm{msm}$ ) en el sur de Perú siguen una economía de coste.

Combinando la información de campo y el SIG concluye que el LCA traza caminos que unen los sitios arqueológicos conocidos y son de mayor eficiencia en coste energético y tiempo que las modernas rutas elegidas por los montañistas. Sin embargo, señala que la calidad del modelo depende del DEM empleado. Un DEM de baja resolución (90 m por píxel) crea rutas rectas, menos efectivas y menos adecuadas a la realidad topográfica que un DEM de mayor resolución (de $30 \mathrm{~m}$ por píxel al menos) (Racoviteanu 2004:121).

Además de la disponibilidad de una cartografía adecuada, las limitaciones del enfoque a nivel general, según Lock y Pouncett (2010), se basan en que el algoritmo no considera la topografía como un todo, sino que se centra en un DEM formado por una miríada de celdas (cells), que toma como referencia una sola celda a la vez y el coste de moverse a las ocho celdas inmediatamente adyacentes a ella. Como resultado, el camino puede no ser realista ya que se traza celda a celda sin considerar una visión más amplia del terreno, circunnavegando hacia arriba y hacia abajo de las pendientes y buscando obviar a toda costa los accidentes del terreno, algo que difícilmente sucede en la realidad.

La crítica entonces gira en torno tanto a la magnitud del espacio a modelar como a la percepción del mismo. El fundamento teórico de la crítica responde a la psicología ecológica de Gibson (1969), la cual entiende que el movimiento no es producto de un cálculo económico, sino de la percepción general del ambiente con una fuerte influencia de la visión. La visión general del terreno y de puntos intermedios al destino produce en quien lo recorre una intencionalidad direccional, la que sumada al destino conocido al cual intenta dirigirse el actor crea un "corredor de intencionalidad" (Lock y Pouncett 2010).

Como sumario de lo anterior, se puede decir que el LCA da una visión aproximada de las elecciones espaciales de las sociedades del pasado para trazar las rutas, debiendo adecuarse a la percepción del paisaje de los seres humanos. Su calidad depende de cuánto se adecue a la topografía, por lo que se necesita una base cartográfica de mayor resolución que la empleada hasta el momento y es imprescindible el trabajo de campo como forma de validar el modelado informático.

Una instancia superadora en este sentido es el trabajo de Moralejo y Gobbo (2015) en el sitio inkaico Shincal, Catamarca, Argentina. Partiendo de una concepción de "paisaje visual" como una forma de interacción social que surge en el marco de relaciones de poder, analizan la visibilidad del sitio desde el camino inkaico mediante SIG y de un DEM de $10 \mathrm{~m}$ de resolución espacial, fotografías aéreas y fotogramas ortorectificados y georreferenciados, datos de relevamiento con estación total de las estructuras del sitio y el modelado de especies vegetales. Modelaron un camino teórico de menor coste (confeccionado a partir de la pendiente, la red hidrográfica, la cobertura vegetal y las construcciones) y desde el mismo la cuenca visual acumulada (la suma de cuencas visuales individuales tomadas cada $10 \mathrm{~m}$ ).

Para poder determinar si el camino arqueológico y el camino modelado presentaban similares patrones de visibilidad fueron comparados estadísticamente mediante una prueba de Bondad de Ajuste de Chi Cuadrado, la cual dio como resultado (valores menores a 0,0001) la diferencia entre ambas, demostrando que los criterios de control de costes fueron de menor importancia que la selección de aquellos lugares desde los cuales eran observados espacios de alta significación como la plataforma ceremonial o el ushnu y la plaza o aukaipata.

\section{Los Caminos Inkaicos del Centro Oeste de Salta}

Para evaluar la capacidad predictiva del LCP se usaron cuatro tramos de caminos inkaicos registrados en zonas áridas y semiáridas de la provincia de Salta, Argentina. En primer lugar, un tramo de $10 \mathrm{~km}$ de largo que asciende desde la base hasta la cima del Volcán Llullaillaco (6.739 msm). En segundo lugar, una sección de más de $20 \mathrm{~km}$ de largo que cruza de norte a sur el Nevado de Acay $(5.715 \mathrm{msm}$ ) y que conecta las tierras altas de la puna con los valles y quebradas secas. En tercer lugar, la conexión Morohuasi-Incahuasi registrada y estudiada por Vitry (2000) de casi $70 \mathrm{~km}$ de 
extensión. En cuarto lugar, el tramo Tastil-Potrero de Payogasta, de $65 \mathrm{~km}$ de $\operatorname{largo}^{2}$ (Figura 1).

El camino inkaico del Volcán Llullaillaco une la base situada a $4.900 \mathrm{msm}$ con la cima a unos $6.715 \mathrm{msm}$ conectando más de 40 estructuras, lo que se conoce como "complejo arqueológico Llullaillaco" (Reinhard y Ceruti 2000). Este rasgo arquitectónico permitió la logística adecuada para el ascenso a la cima y la ofrenda de vidas humanas y objetos materiales dentro del ceremonialismo de alta montaña. El sitio ha sido profundamente estudiado por Ceruti (2003), Reinhard (2010) y Reinhard y Ceruti (2000), por lo que se remite al lector a dichas fuentes.

La montaña se encuentra en la Puna argentina, una depresión geológica de $3.800 \mathrm{~m}$ de altitud media (Cabrera 1957) caracterizada por varios factores de estrés ambiental: una presión atmosférica reducida, alternancia temporal de sequías y heladas, una temperatura diurna ampliamente fluctuante, una reducida humedad (Baied y Wheeler 1993:146), en un relieve donde predominan suelos rocosos y esqueléticos (Cabrera 1957).

Los tres caminos restantes, el del Nevado de Acay, la unión Tastil-Potrero de Payogasta y MorohuasiIncahuasi, se encuentran en el sector centro-oeste de la provincia de Salta, en la provincia geológica de la
Cordillera Oriental (Ramos 2017), limitada hacia el este por las Sierras Subandinas y al oeste por los cordones montañosos de la Puna. Se asientan a su vez a lo largo de ríos de importancia que drenan en los valles y quebradas secos (Quebrada de Humahuaca, Quebrada del Toro, Valles Calchaquíes), canales de comunicación biológica e histórica (Reboratti 2006).

La Cordillera Oriental es el resultado principalmente de la Orogenia Andina que formó la puna, con la diferencia que el manto sedimentario de la Cordillera Oriental es más potente, con pliegues pronunciados y volcados hacia el este que fueron fuertemente erosionados por el drenaje de los ríos que discurren desde las estribaciones orientales de la Puna y que conforman la comunicación natural con los valles (Paoli et al. 2009). En dicho marco encontramos el camino del Nevado de Acay (5.715 msm), conformando la conexión entre las Salinas Grandes, en la Puna de Jujuy hacia el norte, y el Valle Calchaquí hacia el sur. Paralelo a este sistema, a $60 \mathrm{~km}$ al este, se encuentra el tramo MorohuasiIncahuasi.

Este trayecto forma parte del camino inka que ingresa desde las Salinas Grandes en la puna, atravesando el Nevado de Chañi (6.247 msm) hacia el sur. En sus casi 70 $\mathrm{km}$ recorre las márgenes orientales del sistema hidrográfico Rosario-Toro a lo largo de una meseta de $3.200 \mathrm{msm}$ de

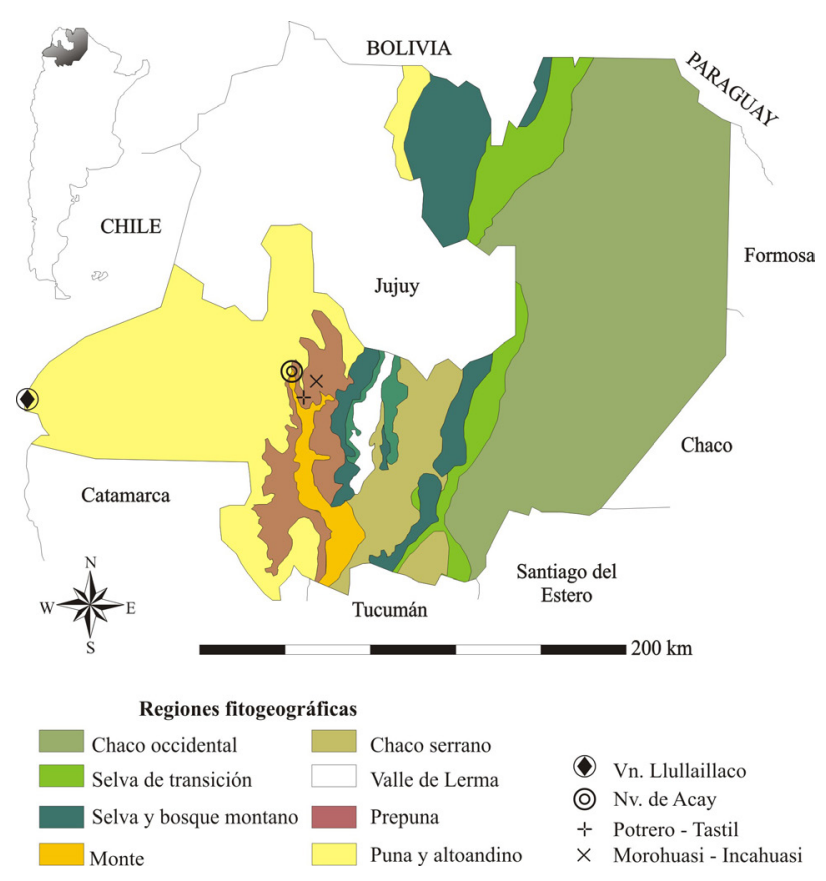

Figura 1. Ubicación de los caminos inkaicos en relación a las regiones fitogeográficas de la provincia de Salta. Dibujo del autor.

Location of the Inka roads in relation to the Phytogeographic regions of the province of Salta. Author's drawing. 
altitud promedio, surcada en sentido este-oeste por gran cantidad de quebradas tributarias a dicho sistema (Vitry 2000). A lo largo de su recorrido conecta distintos sitios de gran magnitud, como tambos y puestos de control que manifiestan las distintas estrategias desplegadas por el estado inkaico para controlar sectores productivos mineros y agrícolas, sujetando a su vez la prestación laboral de las comunidades indígenas locales (Mulvany 2003).

Por su parte, la conexión entre el sitio arqueológico Tastil y Potrero de Payogasta tiene la misma orientación norte-sur, pero a diferencia del anterior, corre con diferencias altitudinales muy marcadas (desde los 2.000 hasta los $4.500 \mathrm{msm}$, en el Abra de Ingañan) por el margen occidental de la Quebrada del Toro, cruzando el accidentado relieve formado por las quebradas fluviales de dirección este oeste, hilvanando sitios intermedios de importancia estratégica para el control económico y político de la zona, como Corral Blanco, Capillas y Corralito (Vitry 2003) ${ }^{3}$.

A esta información se le suma la obtenida por la prospección y registro de $24 \mathrm{~km}$ de camino inkaico en el Nevado de Acay, camino que corre de norte a sur sorteando un desnivel de $1.000 \mathrm{~m}$, desde los $3.800 \mathrm{msm}$ hasta los $4.900 \mathrm{msm}$ (lugar de máxima altitud en el Abra de Acay), para descender nuevamente hasta los $3.800 \mathrm{msm}$, altitud base en ese sector. El trayecto fue registrado mediante un GPS (datum World Geodetic System 1984, elipsoide WGS 84, con proyección EPSG32720, sistema de coordenadas UTM, banda $20 \mathrm{~S}$ ).

\section{Metodología}

La información georreferenciada recabada fue ubicada espacialmente sobre la cartografía digital, creada a su vez de un DEM de alta resolución del satélite ALOS PALSAR (de 12,5 m de resolución espacial) e imágenes satelitales LANDSAT 8 (de $30 \mathrm{~m}$ de resolución espacial, bandas 4 y 5), ambos de acceso libre, que fueron trabajados con una plataforma SIG de código abierto Quantum Gis 2.18.13 Las Palmas de G.C.

Para vislumbrar diferencias en el tipo de suelos atravesados por los caminos se empleó la cartografía digital proporcionada gratuitamente por el INTA (Instituto Nacional de Tecnología Agropecuaria, Argentina) sobre productividad del suelo (escala 1:500.000). En ella se incluye la información relativa al tipo de erosión que sufre cada categoría, la característica de su drenaje, salinidad, acidez, alcalinidad, posición, orden, grupo y subgrupo, etc.

A la cartografía de suelos se le sumó la correspondiente a los ríos y afluentes del Instituto Geográfico Nacional de Argentina (1:250.000, versión digital vectorizada) de la Alta Cuenca del Río Juramento (asiento del camino inkaico del Acay sobre el cauce principal de la Subcuenca Calchaquî), la Subcuenca del Río Rosario-Toro (encajonada por la serranía del Chañi a lo largo de la cual corre el tramo MorohuasiIncahuasi y, siguiendo uno de sus afluentes, discurre la conexión Potrero de Payogasta-Tastil) (Figura2), y la cuenca cerrada de la Puna en su Subcuenca Llullaillaco, asiento del camino que sube al santuario inkaico.

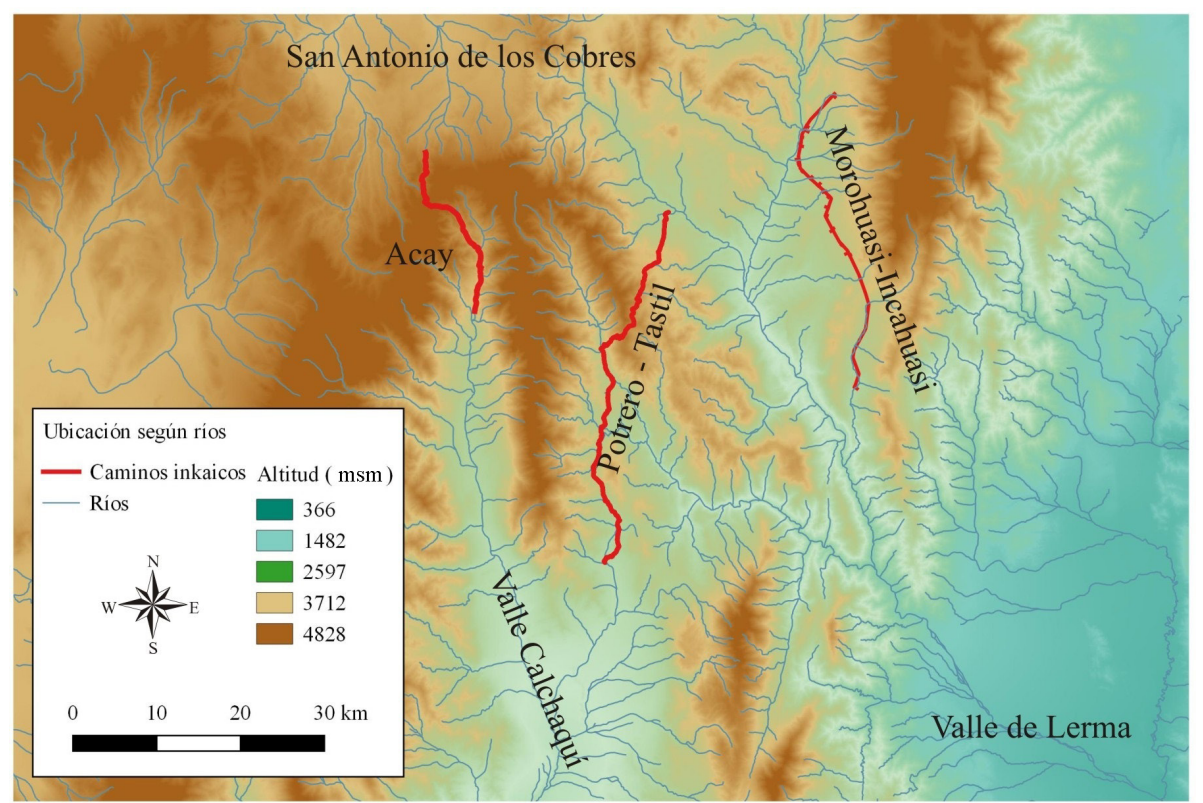

Figura 2. Situación de los caminos inkaicos en relación con los ríos del sistema de la Alta Cuenca del Río Juramento. Dibujo del autor.

Situation of the Inka roads in relation to the rivers of the Upper Juramento River Basin system. Author's drawing. 
Para armar el modelo de caminos óptimos se emplearon como variables la pendiente, el gasto energético-metabólico, la cercanía a fuentes hídricas (modelada a partir del promedio anual del Índice de Vegetación de Diferencia Normalizada o Normalized Difference Vegetation Index, en adelante NDVI), una variable derivada de la pendiente que es el Índice de Rugosidad (Terrain Ruggedness Index, TRI en adelante), la velocidad de marcha a pie calculada para seres humanos y la relativa a camélidos.

El índice o coste energético ( $M$, expresado en watts, creado por Pandolf et al. 1976) se calcula a partir del gasto metabólico que se supone genera el tránsito a baja velocidad llevando una carga a través de determinadas pendientes y topografías. La ecuación toma como base el peso de la persona ( $W$, en $\mathrm{kg}$ ), la carga que lleva $(L$, carga externa en $\mathrm{kg}$ ), la pendiente que atraviesa ( $s$ en porcentaje), su velocidad de marcha ( $v$, en metro sobre segundo) y el coeficiente del terreno ( $\eta$ ).

$$
M=1,5 W+2(W+L)\left(\frac{L}{W}\right)^{2}+\eta(W+L)\left(1,5 v^{2}+0,35 v \cdot s\right)
$$

Los valores que se tomaron como referencia para el modelo son $70 \mathrm{~kg}$ de peso para una persona que lleva una carga de $30 \mathrm{~kg}$, ambos datos de estimaciones sobre el tránsito a los santuarios de altura inkaicos por parte de porteadores experimentados (Ceruti 1999) que caminan a una velocidad de bajo desgaste de $1,3 \mathrm{~m} / \mathrm{s}$, por una pendiente que oscila entre 0 y $60 \%$, a lo largo de un terreno rocoso con un coeficiente $\eta$ de 1,0 (Racoviteanu $2004)^{4}$.

El NDVI muestra la variación en la vegetación a lo largo de una superficie de terreno, con áreas densas caracterizadas por números más altos (cercanos a 1) que las áreas con vegetación más dispersa (hasta -1) (Conolly y Lake 2006:189). Se calcula a partir de las bandas $\mathrm{R}_{\mathrm{NIR}}$ (Reflectance Near-Infrared o reflectancia del infrarrojo cercano) y RRED (Reflectance Red o reflectancia del rojo visible), correspondientes a las bandas 5 y 4 de las imágenes satelitales LANDSAT 8 , con la siguiente fórmula:

$$
\mathrm{NDVI}=\frac{\mathrm{R}_{\text {NIR }} \text { (Reflectance Near Infrared) }- \text { RRed (Reflectance Red) }}{\mathrm{R}_{\mathrm{NIR}}+\text { RRed }}
$$

Esto es un avance con respecto a los antecedentes, ya que en lugar de modelar linealmente los ríos sobre el DEM, se tomó en cuenta una forma más amplia de concentración de recursos que informa sobre la humedad concentrada tanto en el curso de agua como en sus márgenes, dando un panorama más realista de estos ambientes.

Otra variable, TRI, desarrollada por Riley et al. (1999), fue incluida para revelar la distribución de la heterogeneidad del terreno de forma cuantitativa como un indicador extra de la dificultad potencial de atravesar determinado terreno. Se obtiene calculando la diferencia entre el valor de una celda (unidad mínima de un DEM) y la media de las ocho celdas vecinas que la rodean.

Incluimos también el modelado del desplazamiento pedestre mediante la función de coste de Tobler, la cual requiere el empleo de la pendiente, calculada en grados, medida en la relación de cambio vertical dividida el cambio horizontal (valores de la pendiente divididos entre 100) (Herzog 2014). La fórmula de marcha (hiking) de Tobler (1993) indica la velocidad a partir de los valores absolutos de la pendiente:

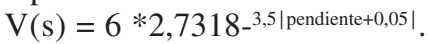

Por último, la importancia del recuso Camelidae en la historia andina desde los tiempos más remotos a la actualidad es muy conocida, al igual que el uso intensivo que hizo el estado inkaico de los camélidos para el tránsito de caravanas, entre otros aprovechamientos económicos. En virtud de esta importancia y para poder establecer si los caminos analizados presentan algún tipo de indicio del empleo de caravanas de llamas como fundamento de sus trazados, se adoptó la fórmula de velocidad de Tripcevich, que al igual que la anterior, está fundamentada en la pendiente:

$$
\text { Tripcevich }=\frac{(4.028 * 46)^{2}}{(\text { pendiente }+4.127)^{2}+46^{2}}
$$

Entonces, con estas variables, pendiente, TRI, gasto energético, NDVI y los cálculos de coste de Tobler y Tripcevich se crearon seis LCP por cada camino inkaico para establecer si el Qhapaq Ñan relevado fue construido siguiendo una ruta de eficiencia energética. La técnica incluye transformar los modelos de terreno en superficies de coste acumulado que expresan la dificultad creciente de moverse desde un punto inicial a uno final trazado en el SIG, mediante una herramienta llamada r.cost.points. El paso siguiente es trazar sobre el raster anterior una línea que representa el camino óptimo con la herramienta r.drain ${ }^{5}$.

Por último, siguiendo la idea de Kondo (2008) que los caminos de menor coste debieran ser reemplazados por corredores de menor coste para ampliar su capacidad predictiva, se experimentó con tres herramientas de uso común en SIG. En primer lugar, para simular la percepción desde los caminos se calcularon cuencas visuales acumuladas (la suma de las celdas visibles desde los sitios asociados a cada camino inkaico) con un alcance máximo de $200 \mathrm{~m}$. En segundo lugar se convirtieron cada uno de los LCP en seis buffer o corredores de ancho variable, desde 100 a $1.000 \mathrm{~m}$, para ver cuál de ellos lograba abarcar al Qhapaq Ñan.

La diferencia entre ambas técnicas es que el buffer no tiene en cuenta la topografía, mientras que la 
cuenca visual toma los valores altitudinales del DEM, proveyendo un resultado más acorde al terreno. De todas maneras, ambos resultaron igualmente válidos $\mathrm{y}$, por economía de procesos, es recomendable la creación de buffers de ancho fijo que son más fáciles de calcular que las cuencas visuales.

En tercer lugar, la información de las medidas estadísticas de posición fue empleada para crear un mapa de sensibilidad arqueológica (MSA). El objetivo del mismo es el de dar una alternativa al LCP cuando este modelado no es del todo preciso para la predicción del Qhapaq Nan. A diferencia de otros modelos predictivos que emplean el cálculo estadístico multivariado (basado principalmente en la regresión logística, Astchul y Nagle 1988; Verhagen 2008), el mapa propuesto se obtiene de forma sencilla cambiando los valores del DEM por la moda estadística.

\section{Resultados}

Los resultados obtenidos nos permiten destacar que los factores que más influyen en el tránsito a lo largo del paisaje son la pendiente y el gasto o costo
A nivel general, los primeros buscan reducir las amplias diferencias altitudinales del mundo andino y se sitúan a niveles relativamente más bajos que los caminos arqueológicos. La longitud de los caminos de menor coste, asimismo, es menor que la de los inkaicos. Lo cual repercute en el mayor gasto energético que exigen los últimos con respecto a los primeros, a pesar de que los cuatros casos arqueológicos y sus modelos se sitúan según su media estadística $(\bar{x})$ en lo que Vitry (2004) clasifica como terrenos llanos (de 0 a $5^{\circ}$ de inclinación), y de pendiente lateral suave (de $5^{\circ}$ a $30^{\circ}$ ) (Tabla 1). En consecuencia, para que el LCP pueda ser un buen predictor del anterior se debe crear alrededor de él un área buffer.

La Tabla 2 presenta los resultados de las áreas buffer creadas para cada LCP y el porcentaje de camino inkaico que cae bajo su extensión. Un buffer de hasta $200 \mathrm{~m}$ de ancho permite tener dentro del alcance visual al Qhapaq Ñan, mientras que un área de cobertura mayor, de $1.000 \mathrm{~m}$ de ancho, escapa a la percepción y debe ser cubierta con prospecciones y revisión de imágenes satelitales o fotos aéreas. Los modelos que más se acercan al trazado del Qhapaq

Tabla 1. Distribución de frecuencias de las variables estudiadas en relación a los caminos.

\begin{tabular}{|c|c|c|c|c|c|c|c|}
\hline \multirow[b]{2}{*}{ Ubicación } & \multirow[b]{2}{*}{ Medida } & \multicolumn{2}{|c|}{ Altitud (m) } & \multicolumn{2}{|c|}{ Gasto energético } & \multicolumn{2}{|c|}{ Pendiente } \\
\hline & & QÑN & LCP & QÑN & $\mathrm{LCP}$ & QÑN & $\mathrm{LCP}$ \\
\hline Acay & $\overline{\mathrm{x}}$ & 4262 & 4220 & 206 & 202 & 30 & 12 \\
\hline Píxeles: QÑN = 3226 & $\hat{\mathrm{x}}$ & 3928 & 3801 & 202 & 202 & 24 & 2 \\
\hline $\mathrm{LCP}=3627$ & $s$ & 416 & 398 & 3 & 2 & 12 & 8 \\
\hline Llullaillaco & $\overline{\mathrm{x}}$ & 5676 & 5524 & 389 & 388 & 19 & 16 \\
\hline Píxeles: QÑN = 835 & $\hat{\mathrm{x}}$ & 5156 & 5168 & 388 & 387 & 17,3 & 11 \\
\hline $\mathrm{LCP}=418$ & $s$ & 427 & 427 & 2,4 & 2,52 & 9,8 & 10 \\
\hline Potrero-Tastil & $\overline{\mathrm{x}}$ & 3500 & 3450 & 509 & 385 & 14 & 7 \\
\hline Píxeles: QÑN = 14056 & $\hat{\mathrm{x}}$ & 3250 & 3254 & 484 & 246 & 8,6 & 1 \\
\hline $\mathrm{LCP}=1037$ & $s$ & 433 & 364 & 195 & 128 & 8 & 5 \\
\hline Morohuasi-Incahuasi & $\overline{\mathrm{x}}$ & 3339 & 3326 & 833 & 413 & 25 & 8 \\
\hline Píxeles: QÑN = 2821 & $\hat{\mathrm{x}}$ & 3437 & 3357 & 813 & 340 & 13 & 5 \\
\hline $\mathrm{LCP}=5983$ & $s$ & 157 & 139 & 321 & 149 & 13 & 6 \\
\hline
\end{tabular}

energético, siendo menos relevantes la rugosidad del terreno (TRI), la concentración de recursos vegetales (NDVI) y la velocidad de marcha, ya sea la determinada por seres humanos a pie (Tobler 1993) o la delineada por la movilidad de una caravana de llamas (Tripcevich 2008). La percepción del espacio en base a la visibilidad, calculada mediante cuencas visuales acumuladas, tampoco jugó un rol fundamental en las construcciones de los caminos. Los caminos de menor coste y los caminos inkaicos no coinciden, sin embargo, al detalle.
Tabla 2. Distribución de porcentajes de tramos abarcados por los buffer.

Distribution of percentages of sections covered by the buffer.

\begin{tabular}{cccc}
\hline \multirow{2}{*}{ Buffer $(\mathrm{m})$} & \multicolumn{2}{c}{ Buffer $(\%)$} & \multirow{2}{*}{ Total } \\
\cline { 2 - 3 } & Afuera & Adentro & \\
\hline Acay (100) & 21 & 79 & 100 \\
\hline Llullaillaco (200) & 49 & 51 & 100 \\
\hline Potrero-Tastil (1.000) & 32 & 68 & 100 \\
\hline Morohuasi-Incahuasi (1.000) & 65 & 35 & 100 \\
\hline
\end{tabular}


Nan son los corredores calculados para el Acay y para Llullaillaco, de 100 y $200 \mathrm{~m}$ de ancho respectivamente, mientras que en los tramos restantes cada buffer tiene que ser ampliado a $1.000 \mathrm{~m}$ de ancho para lograr abarcar porcentajes de $68 \%$ y $35 \%$, de las conexiones PotreroTastil y Morohuasi-Incahuasi, respectivamente.

Para el ascenso al Llullaillaco, el gasto energético de atravesar una pendiente fuerte en un relieve nevado es el factor determinante para la traza solamente del $50 \%$ del camino. Para que el modelo de camino pueda ser un predictor adecuado debe ampliarse como buffer a $200 \mathrm{~m}$ de ancho (Figura 3).

En el caso del Nevado de Acay, como se observa en la Figura 3, el aspecto más relevante del terreno que los constructores del pasado tomaron en cuenta es la pendiente, siendo menos relevantes las variables restantes. Al igual que en el caso anterior, el LCP no coincide al detalle con el camino real, aunque extendiendo su área de influencia a un buffer de $100 \mathrm{~m}$ de ancho lo abarca en un 79\%.

El tramo Potrero-Tastil, por su parte, puede ser abarcado por un buffer de $1.000 \mathrm{~m}$ en un $68 \%$, formado exclusivamente sobre un camino teórico basado en la pendiente. Como se observa en la Figura 4, el camino inkaico se desvía casi $4 \mathrm{~km}$ del LCP en algunos sectores, por lo que la efectividad del mismo como método predictivo dista de ser ideal.

Este hecho es más marcado con el LCP trazado para el camino Morohuasi-Incahuasi. Si bien es la rugosidad del terreno el factor más importante para explicar y predecir la tendencia general del camino inkaico, solamente cae dentro del área buffer el $38 \%$ del recorrido si tomamos un área de $1.000 \mathrm{~m}$ de ancho regular.

Para tratar de inferir los factores naturales que influyen en esta tendencia, mediante la información sobre suelos que se obtuvo con la cartografía del INTA (de 1:500000), se observaron diferencias entre los tipos de caminos en cuanto a la topografía que les sirve de asiento. Mientras que los tramos del Acay y Llullaillaco transitan por afloramientos rocosos en pendientes pronunciadas y laderas escarpadas, los tramos restantes lo hacen en sectores apicales o medios de conos de deyección, en donde el suelo no es rocoso, como en los casos anteriores, sino arenoso.

En otras palabras, cuando el asiento del camino se sitúa en el margen de una quebrada profunda y angosta como es en el caso del Acay, los sectores aptos para construir un tramo que no sufra de anegamientos y transite por una pendiente leve son más limitados que los de aquellos relieves más llanos y superficies amplias donde la pendiente es homogénea, por lo que la predictibilidad es mayor.

El camino del Llullaillaco, por su parte, si bien se asienta sobre roca con cierta presencia de nieve en una ladera empinada, no transita por quebradas ni cauces que generen mayor fricción. Las áreas que presentan mejores condiciones para el ascenso hacia la cima son igualmente restringidas como en el caso anterior.

Por el contrario, cuando se está en presencia de relieves llanos y surcados por cauces de agua, como los conos de deyección en los que se encuentran los tramos Potrero-Tastil y Morohuasi-Incahuasi, las opciones para trasladarse esquivando los meandros y otros accidentes naturales se multiplican ante espacios dilatados ${ }^{6}$.

Existe por lo tanto una correspondencia entre la circunscripción topográfica (asociada a cauces fluviales) y el porcentaje de coincidencia entre los caminos ideales y reales, lo cual indica que la estrategia debe cambiar debido a las limitaciones mismas del modelo teórico predictivo, que calcula solamente un camino a la vez y no contempla alternativas.

En consecuencia, en virtud de que la variable determinante en todos los cálculos anteriores es la pendiente, se propone la superación de un modelo lineal por un modelo areal, recalculando la capa raster de pendientes según las medidas de tendencia central de dicho raster mediante la herramienta estadísticas de zona del SIG, teniendo presente que la distribución de valores en el histograma del mapa de pendientes puede no seguir una curva normal. Cuando esto sucede, no puede emplearse sin recaudo la medida de tendencia central por excelencia, la media muestral $(\bar{x})$ ni la información de dispersión de la desviación estándar $(s)$, por las razones siguientes.

En una distribución normal, los valores centrales, media, mediana y moda coinciden y las observaciones tienden a concentrarse sobre dichos valores: a una desviación estándar de la media $(-1 s$ y $1 s)$ se concentra el $68 \%$ de la muestra, a dos desviaciones estándar $(-2 s, 2 s)$ el $96 \%$ y a tres desviaciones estándar $(-3 s, 3 s)$ el $100 \%$. Pero este modelo teórico es muy pocas veces observado en condiciones que no sean creadas en laboratorio y con muestras muy grandes ( $\mathrm{n}<1.000$ observaciones).

En el caso del histograma de la imagen raster de la pendiente del área investigada en el tramo TastilPotrero (Figura 5), vemos que no coinciden los valores centrales, ya que la media $\bar{x}$ es igual a $18,49^{\circ}$, la moda igual a $2,58^{\circ}$, y la desviación estándar $s$ es igual a 9,91. Si se tiene en cuenta que el valor máximo del raster es de $53^{\circ}$, que la moda se encuentre a dos desviaciones estándar ( $-2 s)$ de la media demuestra que las observaciones están concentradas hacia la izquierda siguiendo una distribución asimétrica positiva, con la correspondiente curva inclinada hacia la izquierda y la cola hacia la derecha.

La inclinación de la curva hacia la izquierda significa que hay una mayor concentración de observaciones en los valores que se ubican hacia la izquierda de $\bar{x}$. En efecto, al estar $\bar{x}$ a dos desviaciones estándar de $(-2 s)$, este 


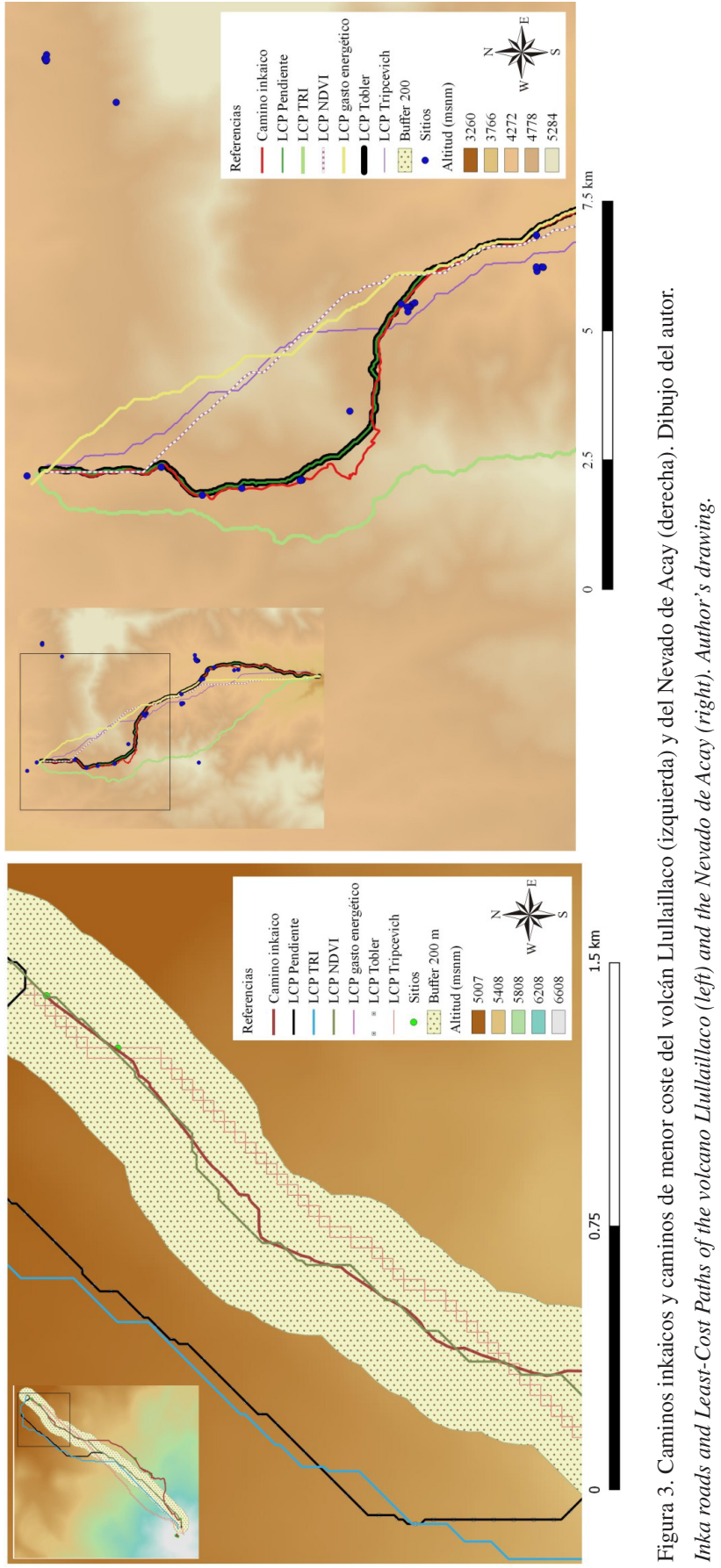




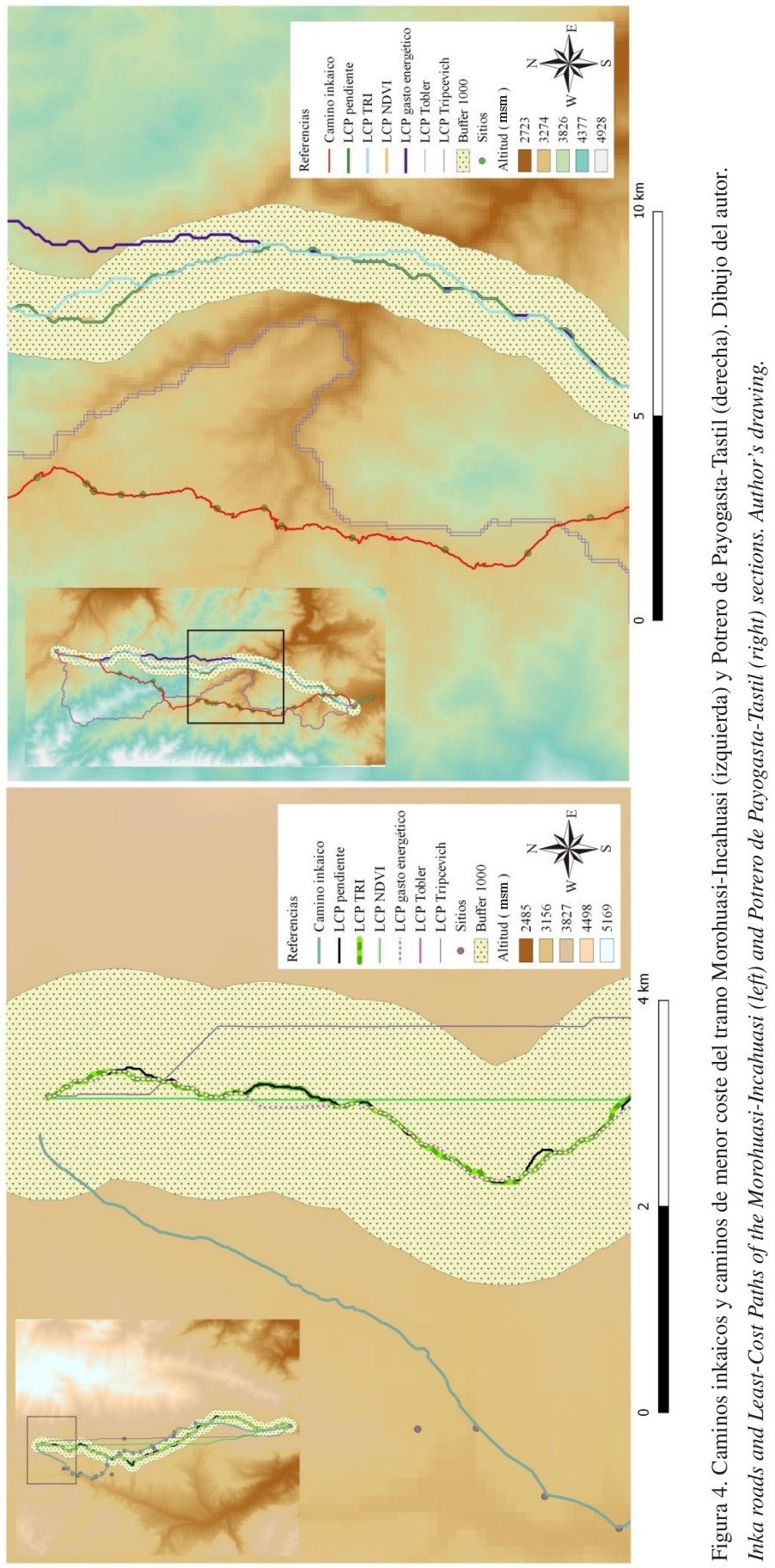




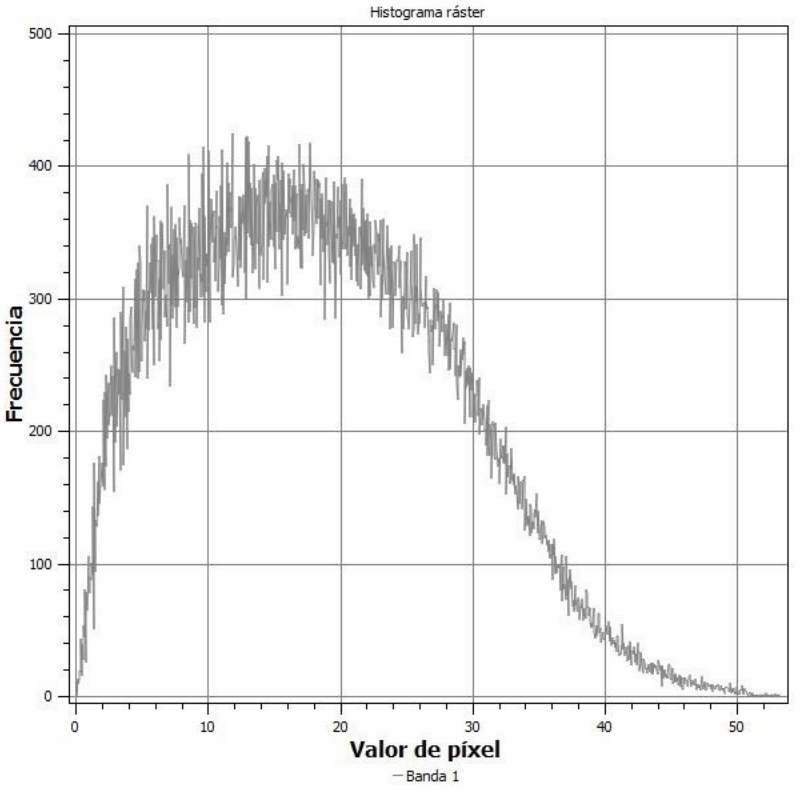

Figura 5. Histograma de la distribución de pendientes del área Potrero-Tastil. Se observa una asimetría positiva (curva hacia la izquierda).

Histogram of the distribution of slopes of the Potrero-Tastil area. A positive asymmetry is observed (curve to the left).

valor no refleja la tendencia central de la distribución, en cambio sí lo hace, que representa los valores que más se repiten en la distribución.

Por lo tanto, y siguiendo con el ejemplo del tramo Morohuasi-Incahuasi, se emplea el valor de la pendiente $(4,57)$ y se crea un raster con la calculadora del SIG, para que el mapa resultante tenga únicamente dos valores, el valor 0 , correspondiente a las áreas que presentan una pendiente mayor a $4,57^{\circ} \mathrm{y}$ el valor 1 a las pendientes de menor inclinación, con la fórmula ("pendiente" $<=$ $4,57)^{*} 1+$ ("pendiente" > 4,57)*0.

$\mathrm{Si}$, por el contrario, se empleasen la $\overline{\mathrm{x}} \mathrm{y}$ la $s$ como referencias para crear la imagen raster según el modelo de la distribución normal de las probabilidades, debido a la concentración de los valores de la distribución a la izquierda tendríamos un mapa muy sobrecargado de información que dificultaría la identificación de áreas puntuales en el terreno (Figura 6).

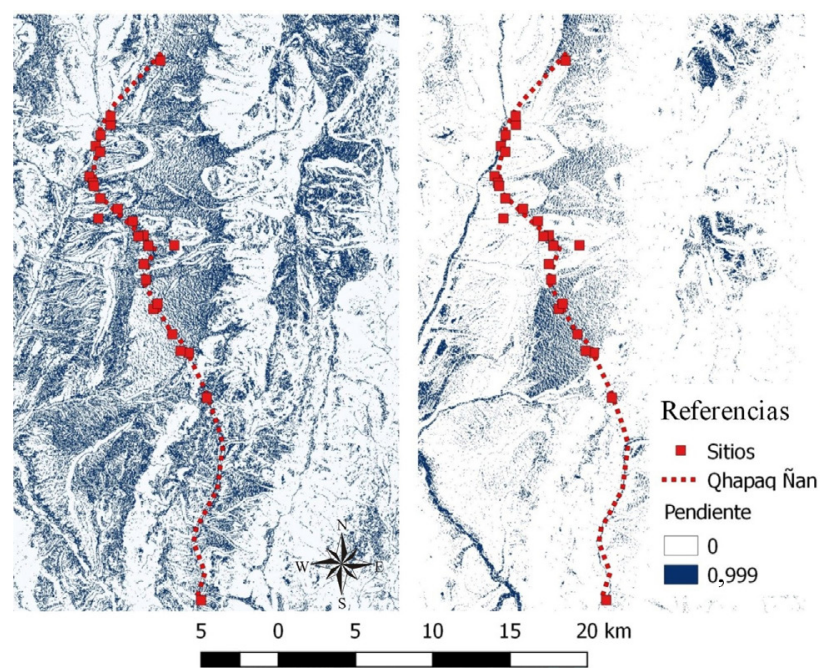

Figura 6. Comparación entre un raster calculado con la desviación estándar (izquierda) y con la moda estadística (derecha). Dibujo del autor.

Comparison between a raster calculated with the standard deviation (left) and with the statistical mode (right). Author's drawing. 
Los valores correspondientes a 1 (una pendiente baja, menor o igual a la moda) pueden transformarse mediante el SIG en coordenadas geográficas y éstas ser traspasadas a un GPS para que el trabajo de prospección en el terreno se dirija a los puntos donde existe una alta posibilidad de encontrar tramos de vías prehispánicas y sitios asociados, facilitando las tareas de registro y conservación tanto para los investigadores de la temática inkaica como para los gestores del patrimonio cultural.

\section{Discusión}

El uso del SIG para explicar problemáticas arqueológicas manifiesta avances y retrocesos dentro un proceso no exento de críticas y revisiones en los últimos 30 años, oscilando entre un uso extendido durante la década de 1980 y principios de 1990, seguido de una crítica severa al enfoque cualitativo y mecanicista de la misma por parte del pos procesualismo y de un resurgir relativamente reciente a fines del 2000 (Verhagen 2017).

Si bien estamos ante un momento de amplio repunte del empleo del SIG en la comunidad arqueológica y de su perfilamiento como una herramienta indispensable para el estudio de la información espacial queda aún la impresión, según Verhagen (2017), que los arqueólogos se encuentran renuentes a la apreciación y adopción del SIG como una metodología con peso específico antes que como una serie de técnicas más o menos facilitadoras de la dispersa información espacial. Es decir, una forma de procesar bases de datos espaciales más que un cuerpo metodológico para dar cuenta de la dimensión espacial de la experiencia humana a nivel general y del cual derivar un cuerpo teórico válido.

A simple vista, los antecedentes recientes en las investigaciones del Qhapaq Ñan parecerían inclinar la balanza hacia la construcción de paisajes sociales mediante una valorización positiva de la experiencia sensible, antes que depositar excesiva confianza en la reducción al ambiente de toda explicación de la movilidad por las arterias estatales. Después de todo, ha sido demostrado no hace mucho que las percepciones humanas (en particular las percepciones visuales) tuvieron gran influencia en la estructuración del espacio (Moralejo 2018; Moralejo y Gobbo 2015; Vitry 2007). Lo cual demuestra las limitaciones que posee el determinismo ambiental subyacente en muchos de las primeras aplicaciones del SIG en problemáticas arqueológicas. Principalmente la noción de que dadas las variables ambientales (tomadas como principales) y culturales (entendidas como secundarias), además de la relación de orden entre las mismas, existía la determinación de las primeras sobre las segundas de manera tal que al estudiar las ambientales podía indicarse de forma probabilística la existencia de las culturales mediante modelos predictivos que tendían a ignorar a su vez el componente simbólico de todo rasgo cultural o mediante su subsunción a lo ambiental (Ebert y Singer 2004; Wheatley 2003).

Sin embargo, las representaciones humanas se encuentran tan ligadas a la experiencia sensorial, y éstas a su vez tan indisolublemente asociadas al marco físico en el que se desenvuelve la vida, que incluso la evaluación de la percepción visual en la revelación u ocultamiento de determinados hitos culturales está sujeta a considerar el ocultamiento topográfico, es decir, lo que se puede ver o no según la situación de lo observado en el paisaje.

Esto significa que, lejos de adherir a una posición arbitrariamente determinista física o fisiográfica, nuestro trabajo ha versado en la visión dialéctica humanos-ambiente, buscando corregir este sobre dimensionamiento de la naturaleza por sobre las cuestiones culturales dentro de un marco interpretativo de la acción humana en conformación dialéctica junto al paisaje, reconociendo también las limitaciones que posee un SIG de incorporar variables no ambientales, tales como las cognitivas o experienciales, lo cual es propio del fuerte componente cuantitativo de sus análisis (Verhagen 2017).

Las limitaciones se plasman en los porcentajes que oscilan entre el 42 y el $20 \%$ de las vías de circulación que no pueden ser explicados por los factores analizados (ni aún siquiera mediante las percepciones sensoriales como el alcance visual). No obstante, lo interesante del enfoque adoptado es que tanto sus alcances como sus limitaciones pueden ser ponderados cuantitativamente $\mathrm{y}$, en consecuencia, mejorados, algo que difícilmente podría ser realizado con otras formas de acercamiento a la problemática de los caminos prehispánicos.

Fuera de lo metodológico, los estudios realizados nos permiten entrever una percepción del paisaje y una valoración subjetiva del mismo que no toma en cuenta variables que en la modernidad toman importancia capital, como la velocidad y su variable asociada, el tiempo. Otro aspecto que pierde entidad por el análisis de más de $150 \mathrm{~km}$ de caminos es el tránsito de caravanas de llamas, un uso de los recursos que pareciera de gran importancia para el estado inkaico en su fase expansiva (Hyslop 1992), pero que al parecer no habría tenido el peso suficiente como para ser el factor principal en la selección de ambientes para trazar las comunicaciones en las arterias analizadas.

Por lo tanto, y con respecto al primer aspecto, la imagen de los constructores de caminos prehispánicos como fríos calculadores economicistas no resiste examen alguno, resaltándose en su lugar la idea de que los paisajes construidos se amoldan a las características físicas del entorno como fruto de una dialéctica milenaria que, antes de rehuir a los obstáculos, los sortea de manera armoniosa. Con respecto a la independencia del modo 
de transitar propio de los camélidos, y sin menoscabo de la importancia económica de ese recurso, pareciera que la predominancia de caminos por pendientes menores a $15^{\circ}$ nos mostraría la importancia del tránsito a pie de elementos de infantería, lo cual sumado a que las vías de comunicación del Tawantinsuyu discurren por las arterías de las cuencas principales, afianzaría la idea del control de un recurso tan fundamental como el agua por parte del Estado cusqueño. Aspectos que el SIG, con sus limitaciones mencionadas, puede dar cuenta satisfactoriamente.

No obstante, un análisis del ejercicio del poder entre los inkas no se agotaría en el control de recursos o en la captación del tributo desde las provincias (en un enfoque exclusivamente material), sino que debe también incluir otros factores que permitan dar cuenta de la complejidad del despliegue del Tawantinsuyu por el sur andino. Una manera de mejorar el enfoque presentado en el futuro debería hacerse mediante un análisis multi criterio, que tome en cuenta tanto los costes ambientales como los socio-culturales, es decir, la consideración de los factores sociales que atraen o repelen la movilidad, como los rituales y simbólicos (Verhagen et al. 2019) por los cuales se justificó la conquista inkaica.

\section{Palabras Finales}

A través de este trabajo de investigación hemos evaluado la aplicabilidad de las técnicas de uso corriente en arqueología para estudiar la comunicación en las sociedades antiguas. Si bien los antecedentes al respecto han tratado con una o pocas variables para el modelado de vías de comunicación y tránsito de poca extensión, hemos aplicado por el contrario seis cálculos complejos para más de $150 \mathrm{~km}$ de caminos inkaicos, lo que nos permite hacer inferencias válidas acerca de dos aspectos: acerca de la relación de las vías con los factores naturales sobre los que se asientan, por un lado, y en lo que respecta a la metodología que da cuenta de estos fenómenos por el otro.

En cuanto a lo primero, el estudio de más de 1.000 km del Qhapaq Ñan nos indica la importancia variable de la topografía, en particular de la pendiente, en la selección de ambientes para trazar los caminos. Medidas de desplazamiento como la velocidad o el tiempo (en el modo de transitar de humanos y camélidos) no resultan de importancia, al menos en los casos analizados, lo cual no debe llevarnos a descartarlos del todo debiendo incluir, en la medida en que un SIG lo permite, otros indicadores de costos sociales como los aspectos ideográficos y socio técnicos (cosmovisión, principios de organización social y política asociados al cuidado de los caminos, prescripciones religiosas sobre el tránsito, entre otros).
La presencia del Qhapaq Nan y sitios asociados en las arterias de mayor caudal hidrográfico del área nos muestra un control directo de los ríos, lo cual fuerza a considerar a futuro nuevas líneas de investigación que desentrañen la manera en la cual el Tawantinsuyu pudo ejercer dicho control en zonas con una tradición de ocupación densa y muy anterior al advenimiento del mismo, como el Valle Calchaquí y en menor medida el Valle de Lerma.

En cuanto a lo segundo, los aspectos metodológicos, se puede decir que usado con recaudos el LCP es útil para reducir la búsqueda arqueológica de áreas de gran extensión a unos pocos metros, economizando esfuerzo y recursos materiales al indicar de antemano la probabilidad de hallar en el terreno los indicadores arqueológicos a través de software y cartografía de alta resolución gratuitos, en lugar de emplear medios de alto costo y complejidad (como drones o imágenes satelitales de alta resolución), favoreciendo por igual tanto a la investigación del terreno como a la gestión patrimonial.

Sin embargo, el proceso de generar un modelo predictivo del Qhapaq Nan no puede ser automático ya que un cálculo de caminos de menor coste es un modelo ideal, una aproximación a la realidad, por lo que es necesario tener en cuenta la topografía de la zona y en base a eso desarrollar corredores de menor coste (áreas buffers de ancho limitado) o bien mapas de sensibilidad arqueológica, además de considerar otras variables ambientales difíciles de modelar, como la vegetación o el tipo suelo.

El conocimiento de primera mano del terreno es, por su parte, fundamental para obtener resultados más satisfactorios. Como hemos visto, para un relieve deprimido circunscrito a cauces fluviales, el LCP puede resultar un buen predictor si se lo acompaña de un cálculo de buffer. En cambio, para relieves más amplios sometidos a la erosión fluvial, es útil un mapa de sensibilidad arqueológica en los cuales la presencia de ríos significa un obstáculo antes que una vía de comunicación.

Por todo esto, la eficacia del modelo para un investigador es inversamente proporcional a la complejidad de su confección, ya que si bien el LCP tiene un valor predictivo muy alto requiere conocimientos avanzados en el uso de SIG y cierto tiempo al frente de un ordenador, mientras que la técnica de cambiar los valores del raster de pendientes es un proceso simple y rápido, pero requiere mayores recursos en términos de prospecciones en el terreno, revisión de imágenes satelitales y fotografías aéreas.

Agradecimientos: Agradezco al Consejo Nacional de Investigaciones Científicas y Técnicas de Argentina por las sucesivas becas que permitieron realizar mis investigaciones. A los evaluadores del manuscrito, 
cuyas acertadas apreciaciones permitieron mejorar el trabajo. A las Dras. María Ester Albeck y Sara Mata, por acceder a dirigir estas investigaciones y por su apoyo generoso y constante. Al Lic. Christian Vitry por compartir generosamente la información de campo del proyecto Qhapaq Nan de Salta. A la directora del Museo de Antropología de Salta-Argentina, Lic. Mirta Santoni, por otorgar los permisos de excavación correspondientes. A la familia Borelli, por los permisos para investigar en el Acay y por su generosidad. A los Dres. Federico Restifo y Cecilia Mércuri por la lectura del manuscrito y sus valiosas sugerencias.

\section{Referencias Citadas}

Altschul, J.H. y C.L. Nagle 1988. Collecting new data for the purpose of model development. En Quantifying the Present and Predicting the Past: Theory, Method, and Application of Archaeological Predictive Modeling, editado por L.W.J. Judge y J.H. Sebastian, pp. 257-300. U.S. Department of the Interior, Bureau of Land Management, Washington DC.

Baied, C.A. y J.C. Wheeler 1993. Evolution of High Andean Puna Ecosystems: environment, climate, and culture change over the last 12,000 years in the Central Andes. Mountain Research and Development, Vol. 13, No. 2, Mountain Geoecology of the Andes: Resource Management and Sustainable Development, pp. 145-156. International Mountain Society and the United Nations University, Boulder.

Cabrera, A. 1957. La vegetación de la Puna Argentina. Revista de Investigaciones Agrícolas XI (4).

Ceruti, C. 1999. Cumbres Sagradas del Noroeste Argentino. Avances en Arqueología de Alta Montaña y Etnoarqueología de Santuarios de Altura Andinos. Editorial de la Universidad de Buenos Aires, Buenos Aires.

Ceruti, M.C. 2003. Llullaillaco. Sacrificio y Ofrendas en un Santuario Inca de Alta Montaña. EUCASA, Salta.

Conolly, J. y M. Lake 2006. Geographical Information Systems in Archaeology. Manuals in Archaeology, Cambridge University Press, Cambridge.

De Feo, M.E. y D. Gobbo 2007. Diseño de un modelo predictivo para la localización de tramos de vialidad incaica mediante la utilización de SIG. Primer Congreso Argentino de Arqueometría: Metodologías Científicas Aplicadas al Estudio de Bienes Culturales, pp. 37-61. Humanidades y Artes Ediciones, Rosario.

Ebert, J., S. Larralde y L.Wandsnider 1987. Distribution archaeology: Survey, mapping and analysis of surface archaeological materials in the Green River Basin, Wyoming. En Perspectives on Archaeological Resources Management in the “Great Plains", editado por A. Osborn y R. Hassler, pp. 159-177. I \& O Publishing Company, Omaha.

Ebert, D. y M. Singer 2004. GIS, Predictive modelling, erosion, site monitoring. Assemblage, The Sheffield Graduate Journal of Archaeology 8:19-40.

Fitzhugh, B., V.L. Butler, K.M. Bovy y M.A. Etnier 2019. Human ecodynamics: A perspective for the study of long-term change in socioecological systems. Journal of Archaeological Science 23:1077-1094.

Gibson, E.J. 1969. Principles of Perceptual Learning and Development. Appleton-Century Crofts, New York.

Herzog, I. 2014. A review of case studies in archaeological Least-Cost Analysis. Archeologia e Calcolatori 25:223-239.

Howey, M.C.L. 2007. Using Multi-Criteria Cost Surface Analysis to explore past regional landscapes: A case study of ritual activity and social interaction in Michigan, AD
1200-1600. Journal of Archaeological Science 34 (11):18301846.

Hyslop, J. 1992. Qhapaqñan, el Sistema Vial Inkaico. INDEA, Lima.

Kondo, Y. 2008. Rethinking GIS-based Travel Cost Modeling. 24th Semiannual Meeting of Japan Society for Archaeological Information, Keio University, Tokyo.

Lock, G. y J. Pouncett 2010. Walking the Ridgeway revisited: The methodological and theoretical implications of scale dependency for the derivation of slope and the calculation of Least-Cost Pathways. En Making History Interactive, editado por B.D. Frischer, J.W. Crawford y D. Koller, pp. 192-203. Archaeopress, Oxford.

Lucero, G., E. Marsh y S. Castro 2014. Rutas prehistóricas en el NO de San Juan: Una propuesta macrorregional desde los Sistemas de Información Geográfica. En Arqueología de Ambientes de Altura de Mendoza y San Juan (Argentina), editado por V. Cortegoso, V. Durán y A. Gasco, pp. 275-305. EDIUNC, Mendoza.

Matos, R. 2015. El Qhapaq Ñan del Tawantinsuyu: Reflexiones sobre su significado político y social en el presente andino. Revista de Antropología del Museo de Entre Ríos 1:12-20.

Matsumoto, G. 2008. Availability of Least-cost Pathway Analysis for the Study of Inka Road System. 36th Annual Midwest Conference on Andean and Amazonian Archaeology and Ethnohistory, University of Wisconsin. ttps://www.academia.edu/326547/Availability_of_ Least-Cost_Pathway_Analysis_for_the_Study_of_Inka_Road_ System (24 de marzo de 2020).

Magee, S. 2015. How do I get to Vilcashuaman? Least Cost Path Analyses of the Chinchaysuyu Road from Cuzco to Vilcashuaman. Master's thesis, University of Colorado Boulder, Boulder.

Moralejo, R. 2018. Un modo de pensar los caminos. Cuadernos del Instituto Nacional de Antropología y Pensamiento Latinoamericano 6 (1):21-36.

Moralejo, R. y J.D. Gobbo 2015. El Qhapaq Nan como espacio de poder de la política incaica. Estudios Atacameños 50:131-150.

Mulvany, E. 2003. Control estatal y economías regionales. Cuadernos 20:173-197.

Pandolf, K.B., G.B. Givoni y R.F. Goldman 1977. Predicting energy expenditure with loads while standing or walking very slowly. Journal of Applied Physiology 43 (4):577-581.

Paoli, H.P., N. Volante, Y.E. Noe, L.M. Vale, S. Castrillo y R. Osinaga 2009. Adecuación a un Sistema de Información Geográfica del Estudio "Los Suelos del NOA (Salta y Jujuy), Nadir A. - Chafatinos T., 1990”. Instituto Nacional de Tecnología Agropecuaria, Salta.

Parcak, S.H. 2009. Satellite Remote Sensing for Archaeology. Routledge, London and New York.

Racoviteanu,A.E. 2004. Sacred Mountains and GlacialAarchaeology in the Andes. Master's thesis, Department of Geography, Faculty of the Graduate School, University of Colorado, Denver. 
Rademaker, K., D.A. Reid y G.R.M. Bromley 2012. Connecting the dots: Least Cost Analysis, paleography, and the search for Paleoindian Sites In Southern Highland Peru. En Least Cost Analysis of Social Landscapes: Archaeological Case Studies, editado por S. L. Surface-Evans y D.A. White, pp. 32-45. University of Utah Press, Salt Lake City.

Ramos, V.A. 2017. Las provincias geológicas del noroeste argentino En Ciencias de la Tierra y Recursos Naturales del NOA. Relatorio del XX Congreso Geológico Argentino, editado por C. M. Muruaga y P. Grosse, pp. 42-56. Consejo Profesional de Ingenieros y Geólogos de Mendoza, San Miguel de Tucumán.

Reboratti, C. 2006. Situación ambiental en las ecorregiones Puna y Altos Andes. En La Situación Ambiental Argentina 2005, editado por A. Brown, U. Martinez Ortiz, M. Acerbi y J. Corcuera, pp. 33-39. Fundación Vida Silvestre Argentina, Buenos Aires.

Reinhard, J. y C. Ceruti 2000. Investigaciones Arqueológicas en el Volcán Llullaillaco. Complejo Ceremonial Incaico de Alta Montaña. EUCASA, Salta.

Reinhard, J. y M.C. Ceruti 2010. Inca Rituals and Sacred Mountains: A Study of the World's Highest Archaeological Sites. Cotsen Institute of Archaeology Press, University of California, Los Angeles.

Riley, S., S. DeGloria y R. Elliot 1999. A Terrain Ruggedness Index that quantifies topographic heterogeneity. Intermountain Journal of Sciences 5 (1-4):23-27.

Stanish, C., E. de la Vega, M. Moseley, P. Williams, C. Chávez, B. Vining y K. Lafavre 2010. Tiwanaku Trade Patterns in Southern Peru. Journal of Anthropological Archaeology 29 (4):524-532.

Tobler, W. 1993. Three presentations on geographical analysis and modeling: Non-isotropic geographic modeling; speculations on the geometry of geography; and global spatial analysis. Technical Report 93 (1): $3-26$

Tripcevich, N. 2008. Estimating llama caravan travel speeds: ethnoarchaeological fieldwork with a Peruvian salt caravan. Trabajo presentado en la Inauguración del Center for Spatial Studies (spatial@ucsb), University of California, Santa Bárbara. https:// mapaspects.org/book/export/html/206/index.html (24 de marzo de 2020).
Verhagen, P. 2008. Testing archaeological predictive models: a rough guide. En Layers of Perception. Proceedings of the 35th International Conference on Computer Applications and Quantitative Methods in Archaeology (CAA), editado por A. Posluschny, K. Lambers e I. Herzog, pp. 285-291. Verlag Dr. Rudolf Habelt GmbH, Bonn.

Verhagen, P.L. 2017. Spatial Analysis in Archaeology: Moving into New Territories. Digital Geoarchaeology 11-25.

Verhagen, P., L. Nuninger y M.R. Groenhuijzen 2019. Modelling of pathways and movement networks in archaeology: An overview of current approaches. En Finding the Limits of the Limes Modelling Demography, Economy and Transport on the Edge of the Roman Empire, editado por P. Verhagen, J. Joyce y M. R. Groenhuijzen, pp. 217-249. Springer, New York.

Vitry, C. 2000. Aportes para el Estudio de Caminos Incaicos. Tramo Morohuasi-Incahuasi. Salta-Argentina. Gófica Editores, Salta.

Vitry, C. 2003. Aportes sobre el despoblamiento de la localidad arqueológica de Tastil. Revista de la Escuela de Historia 2 (1), edición digital, http://www.unsa.edu.ar/histocat/revista/revista0214. htm (10 de octubre de 2018).

Vitry, C. 2004. Propuesta metodológica para el registro de caminos con componentes inkas. Andes 15. https://www.redalyc. org/pdf/127/12701507.pdf (24 de marzo de 2020)

Vitry, C. 2007. Caminos rituales y montañas sagradas. Estudio de la vialidad inka en el Nevado de Chañi. Boletín del Museo Chileno de Arte Precolombino 12 (2):69-84.

Wheatley, D. 2003. Making space for an archaeology of place. Internet Archaeology 15. https://eprints.soton.ac.uk/28800/1/ Wheatley_IA15.pdf (24 de marzo de 2020).

Wheatley, D. y M. Gillings 2004. Spatial Technology and Archaeology. The archaeological applications of GIS. Taylor \& Francis, New York.

White, D.A. 2012. Prehistoric trail networks of the Western Papaguería: A multifaceted Least Cost Graph Theory Analysis. En Least Cost Analysis of Social Landscapes: Archaeological Case Studies, editado por S.L. Surface-Evans y D.A. White, pp. 188-208. University of Utah Press, Salt Lake City.

\section{Notas}

${ }^{1}$ El estudio y modelado de los aspectos ambientales que favorecen o constriñen la movilidad se emplean en arqueología con creciente profusión desde la década de 1990, por lo que un recuento pormenorizado de los trabajos respectivos sobrepasa los límites de este trabajo. Por esta razón remitimos al lector a la revisión exhaustiva de Verhagen (2008) y de Verhagen, Nuninger y Groenhuijzen (2019).

${ }^{2}$ El tramo de camino inkaico del Nevado de Acay fue prospectado por el autor. La información acerca de las conexiones entre Tastil y Potrero de Payogasta y el camino hacia el santuario del volcán Llullaillaco, fue generosamente aportada por el Lic. Christian Vitry, jefe del proyecto Qhapaq Ñan, Secretaria de Patrimonio Cultural, provincia de Salta. El tramo Morohuasi-Incahuasi fue reconstruido de la publicación del mismo investigador (Vitry 2000) y del estudio de imágenes satelitales Landsat 8 y de Google Earth Pro

${ }^{3}$ Los datos espaciales de estos dos tramos fueron proporcionados gentilmente por el Lic. Christian Vitry, director del Proyecto Qhapaq Ñan. La información digital proporcionada tiene formato kmz de Google Earth, en coordenadas sexagesimales del sistema geodésico WGS 84. Fue transformada al formato .shp de ESRI y a coordenadas UTM. Por su parte, el camino que une las localidades de Morohuasi e Incahuasi fue digitalizado a partir de las coordenadas geográficas publicadas por Vitry (2000).
${ }^{4}$ Por la presencia de nieve en su cima, para el caso Llullaillaco el valor del coeficiente $\eta$ elegido fue 3,3 , coeficiente con el que se modela la presencia de nieve blanda (Racoviteanu 2004:110)

${ }^{5}$ Los valores del NDVI fueron transformados mediante la operación trigonométrica arcocoseno antes de calcular el LCP. Dicha transformación permite que se alteren los valores de las áreas de mayor vegetación cercanos a 1, ya que los valores cercanos a 1 son ignorados por el LCP, al contrario de los valores cercanos a 0 . De esta forma las áreas de concentración de recursos hídricos y de vegetación toman valores cercanos a 0 , mientras que aquellos con vegetación dispersa, tienden a 1. Los dos cálculos, de gasto energético y NDVI, fueron realizados con la calculadora geodésica del SIG.

${ }^{6}$ En este sentido, Vitry (2000) en su estudio del tramo MorohuasiIncahuasi describe la presencia de caminos paralelos y alternativos a la ruta troncal. Además resalta el carácter zigzagueante en algunos sectores, que sirve para sortear quebradas profundas o pendientes fuertes. Se observa entonces que la conexión lineal y directa puede hacerse en la medida en que el camino siga un relieve acorde, mientras que las formas más accidentadas del relieve redundan en vías de comunicación de sentido más errático. 